\title{
Família e atençáo psicossocial: o cuidado à pessoa que faz uso abusivo de álcool e outras drogas
}

\author{
Meyrielle Belotti, Higor Lucio Fraga, Lorrayne Belotti \\ Universidade Federal do Espírito Santo - UFES, Vitória, ES, Brasil.
}

\begin{abstract}
Resumo: Objetivo: Discutir e analisar a produção científica nacional existente sobre o papel da família e sua influência no processo de cuidado do seu ente com necessidades decorrentes do uso abusivo de drogas nos serviços de saúde mental. Método: Foi realizada uma revisão integrativa da literatura por meio de consulta às bases de dados SciELO, LILACS e Biblioteca Virtual em Saúde. A análise dos dados deu-se por meio da técnica da análise do conteúdo, sendo identificadas quatro categorias: 1) o convívio em família e suas demandas; 2) as estratégias de cuidado ofertadas às famílias; 3) dificuldades para a inserção da família no tratamento do seu ente; e 4) a inserção da família no tratamento: quais os benefícios? Resultados: Os resultados indicam que a participação da família no processo de cuidado do seu ente pode proporcionar melhorias no seu tratamento, dando-lhe apoio e suporte, além de favorecer a adesão ao tratamento. Conclusão: Há a necessidade de investimentos em estratégias de cuidado centradas nas reais demandas da família, e não apenas como mais uma ação enfocada no manejo com o seu familiar com necessidades decorrentes do uso do álcool e outras drogas.
\end{abstract}

Palavras-chave: Serviços de Saúde Mental, Drogas Ilícitas, Relações Familiares.

\section{Family and psychosocial attention: care for the person with abusive use of alcohol and other drugs}

\begin{abstract}
Objective: To discuss and analyze the existing scientific literature on the role of the family and its influence on the care process of a relative due to drug abuse, in mental health services. Method: We conducted an integrative literature review through consultation with the databases SciELO, Lilacs and Virtual Health Library. Data analysis used the content analysis technique, four categories were identified: 1) family conviviality and their demands; 2) care strategies offered to the families; 3) difficulties for the family's insertion in the relative's treatment; and 4) benefits of family involvement in the treatment. Results: The results indicate that family involvement can improve their treatment, providing support and support, and promote adherence to treatment. Conclusion: We conclude that there is need for investment in care strategies focused on the actual family demands.
\end{abstract}

Keywords: Mental Health Services, Street Drugs, Family Relations. 


\section{Introdução}

Atualmente, o uso abusivo do álcool e outras drogas tem se configurado como um dos mais importantes problemas de saúde pública no mundo, considerando-se a magnitude e a diversidade de aspectos envolvidos (RAUPP; COSTA, 2006). Nesse sentido, estudos epidemiológicos têm contribuído para a descrição desse fenômeno, bem como para a análise de mudanças no padrão de consumo. De acordo com Levantamento Nacional de Álcool e Drogas (LENAD), realizado no ano de 2012 pela Universidade Federal de São Paulo (UNIFESP), por meio do Instituto Nacional de Políticas Públicas de Álcool e Outras Drogas (INSTITUTO..., 2012), estima-se que $17 \%$ da populaçáo brasileira faça uso de forma abusiva e/ou dependente de álcool, dos quais $9 \%$ afirmam que o uso de álcool já teve efeito prejudicial na sua família.

No Brasil, as políticas públicas de saúde direcionadas para a temática do álcool e outras drogas estáo articuladas ao campo da saúde mental. Nesse contexto, a Lei $n^{\circ} 10.216 / 2001$ constitui-se como um marco institucional por dispor sobre a proteção e os direitos das pessoas em sofrimento psíquico, entre elas as pessoas com necessidades decorrentes do uso do álcool e outras drogas, propondo a substituição dos manicômios pela criação de rede de atenção composta por dispositivos de caráter extra-hospitalares, conforme preconizado pelo Movimento da Reforma Psiquiátrica Brasileira (BRASIL, 2004a, 2001).

Dentro dessa proposta, a atenção psicossocial se caracteriza por ser um modelo norteado do cuidado, constituindo-se como um conjunto de açóes teórico-práticas, político-ideológicas e éticas que considera, prioritariamente, a pessoa em sofrimento (YASUI; COSTA-ROSA, 2008). Assim, esse modelo busca a reformulação das açôes de caráter técnico, por meio da reorganização dos serviços em rede de base territorial e do reconhecimento da pessoa em sofrimento psíquico e com necessidades decorrentes do uso do álcool e outras drogas como um ser com história de vida e possuidor de desejos.

Nesse cenário, os Centros de Atençáo Psicossocial (CAPS) assumem um papel estratégico na consolidaçáo do modelo da atenção psicossocial, pois se configuram como um serviço de referência e para o cuidado de pessoas com sofrimento psíquico e com necessidades decorrentes do uso do álcool e outras drogas. Seu objetivo é a oferta de cuidado para uma população de um território de abrangência, no qual serão realizados o acompanhamento clínico e a busca da reinserção social (BRASIL, 2004b).
Atualmente, os CAPS, por meio da promulgação da Portaria no 3.088, de dezembro de 2011, compóem a Rede de Atenção Psicossocial (RAPS), que surge com o objetivo de criar, ampliar e articular pontos de atenção à saúde para pessoas com sofrimento psíquico e com necessidades decorrentes do uso abusivo de álcool e outras drogas no âmbito do SUS. Nesse rearranjo, além dos CAPS, são elencados como principias pontos de atenção: as Unidades Básicas de Saúde; os Núcleos de Apoio à Saúde da Família; Consultórios da rua; Centros de Convivência; Atenção de Urgência e Emergência; Unidades de Acolhimento; Serviços de atenção em regime residencial; Leitos de saúde mental, álcool e outras drogas em Hospitais Gerais e Serviços Residenciais Terapêuticos (BRASIL, 2011).

No que se refere, especificamente, à produção de cuidado sobre a temática do álcool e outras drogas, em 2003, o Ministério da Saúde lançou a Política de Atençáo Integral a Usuários de Álcool e Outras Drogas, com a proposta de realizar um cuidado integral e articulado na perspectiva da redução de danos. Entende-se a redução de danos como uma estratégia de cuidado que visa implantar açóes preventivas e redutoras das consequências negativas associadas ao uso do álcool e outras drogas; assim, busca reconhecer cada usuário em suas singularidades, com uma proposta orientada pelo respeito à liberdade de escolha, sem, necessariamente, interferir na oferta ou consumo (BRASIL, 2003).

Nesse cenário, em que se observa a busca pela consolidação do processo de desinstitucionalização, com ênfase no desenvolvimento de práticas que favoreçam a inserção das pessoas com sofrimento psíquico no seu território, garantindo sua livre circulação pelos diversos equipamentos de saúde, comunidade e cidade, verifica-se uma mudança no papel da família para com o tratamento do seu ente. Assim, a família, que antes era entendida como um fator desencadeador da problemática em questão, passa a ter que exercer o papel de apoio ao seu membro, além de ser caracterizada como o primeiro lugar de intervenção, recebendo maior atenção dos serviços de saúde mental (CONSTANTINIDIS; ANDRADE, 2015).

De acordo com Bernardi (2002), a inserção da família no processo de cuidado, em um primeiro momento, está no esforço mútuo de apoio e motivação ao seu ente com necessidades decorrentes do uso de álcool e outras drogas. O autor ressalta ainda que considerar a família no tratamento significa envolvê-la nas atividades ofertadas pelos serviços de atençáo em saúde mental, para que ela acompanhe as estratégias de cuidado destinado ao seu membro.

Nesse contexto, acredita-se que as açóes dirigidas à família da pessoa com necessidade decorrentes do uso do álcool e outras drogas devem ser estruturadas 
de maneira a favorecer e a potencializar a relaçáo familiar/profissional/serviço, sendo o familiar compreendido como um parceiro singular e participativo no processo do cuidado dispensado ao seu membro e que também necessita de cuidados. Com base no exposto, o objetivo do estudo foi discutir e analisar a produção científica nacional existente sobre o papel da família e sua influência no processo de cuidado do seu ente com necessidades decorrentes do uso de drogas nos serviços de saúde mental.

\section{Método}

Para alcançar os objetivos traçados neste estudo, optou-se por uma revisão integrativa da literatura fundamentada na análise de conteúdo. Esse método de pesquisa permite a síntese de diversos estudos publicados em dado momento a respeito de uma temática específica. Sua proposta inicial consiste na apresentação em

[...] resumo das evidências relacionadas a uma estratégia de intervenção específica, mediante a aplicação de métodos explícitos e sistematizados de busca, apreciação crítica e síntese da informaçáo selecionada (RUSSEL, 2005, p. 08).

Tal técnica é constituída de cinco fases: elaboração da pergunta norteadora; busca ou amostragem na literatura; revisão e seleçáo dos estudos; análise de dados; e apresentação dos resultados (RUSSEL, 2005).

\subsection{Elaboração da pergunta norteadora}

Com base na revisão integrativa proposta por Russel (2005), a pergunta norteadora dá início ao estudo, contribuindo para a busca de respostas por meio de hipóteses levantadas acerca de um tema proposto. Com isso, o estudo teve como questôes norteadoras: como ocorre a participaçâo da família no processo de cuidado de um dos seus membros, com necessidades decorrentes do uso do álcool e outras drogas? Qual é a sua influência nesse processo?

\subsection{Busca ou amostragem na literatura}

Essa etapa também pode ser entendida como a busca de evidências, ou seja, artigos em consonância com objetivo do estudo por meio do uso de palavras-chave e aplicação dos critérios de inclusão (RUSSEL, 2005). A busca foi realizada nas bases de dados SciELO (Scientific Eletronic Library
Online), LILACS (Literatura Latino-Americana e do Caribe em Ciências da Saúde) e na Biblioteca Virtual em Saúde, no período de março a maio de 2015. Os critérios de inclusão foram somente os artigos científicos de origem brasileira, em português, publicados entre os anos de 2005 a 2015, com disponibilidade on-line do texto completo. As palavras-chave utilizadas foram: "álcool e outras drogas" e "Centro de Atençáo Psicossocial Álcool e outras Drogas". O termo "família" foi utilizado apenas na etapa seguinte de revisão e seleção dos artigos, para um melhor recorte e com objetivo de ampliar a busca inicial.

\subsection{Revisão e seleção dos estudos}

Após a busca inicial, a etapa de revisão e seleção buscou delimitar e organizar os dados por meio da seleção de artigos, avaliação dos títulos e leitura dos resumos. Nessa etapa, foram selecionados artigos cuja discussão era fundamentada na Política de Atenção Integral a Usuários de Álcool e Outras Drogas. Ainda, foram incluídos os artigos que relacionavam a temática do uso de álcool e outras drogas com a inserção da família no processo de cuidado de seu ente.

\subsection{Análise de dados}

A análise dos dados foi orientada pela Análise de Conteúdo proposta por Bardin (2009) e organizada em torno de três momentos: 1. A pré-análise; 2. A exploração do material; 3 . O tratamento dos resultados: a inferência e a interpretação. $\mathrm{Na}$ fase $\mathrm{da}$ pré-análise, foi realizada uma leitura flutuante dos artigos selecionados, com o recorte dos trechos que contemplavam o objetivo do estudo e a sua inclusão na tabela. $\mathrm{Na}$ fase de exploração do material, foi feita a categorização do conteúdo; por último, foi aplicada a fase do tratamento dos resultados e interpretação, que se configurou na análise reflexiva e crítica, com a condensação e o destaque das informaçóes para análise, culminando nas interpretações inferenciais.

\section{Resultados e Discussão}

Foram encontrados 387 artigos, sendo 68 eliminados por se repetirem nas bases de dados. Além disso, outros 101 artigos foram excluídos, pois não traziam discussóes à luz da Política de Atenção Integral a Usuários de Álcool e Outras Drogas, e 41 não estavam disponíveis na íntegra. Assim, foram selecionados 177 artigos para leitura do resumo. Após a realização dessa etapa, 160 foram excluídos, visto que não 
debatiam a participação da família no processo do cuidado. Dessa forma, restaram 17 artigos pertinentes ao objetivo deste estudo (Tabela 1).

As categorias foram delineadas não necessariamente pela repetição dos conteúdos, mas pela sua relevância no encaminhamento das discussões. Diante disso, após a exploração do material, foram criadas as seguintes categorias: (1) o convívio em família e suas demandas; (2) as estratégias de cuidado ofertadas às famílias; (3) dificuldades para a inserção da família no tratamento do seu ente; (4) inserção da família no tratamento: quais os benefícios?

\subsection{O convívio em família e suas demandas}

Esta categoria incorpora os dados/artigos que dizem respeito às necessidades dos familiares diante do cotidiano vivenciado com o ente com necessidade decorrentes do uso do álcool e outras drogas. Um dos dados encontrados relacionado à demanda familiar refere-se ao desejo de ajudar o seu membro (REIS; MOREIRA, 2013). O termo "ajudar" no dicionário significa auxiliar, apoiar, socorrer e assistir (FERREIRA, 1988). Assim, os familiares, ao ajudarem seu ente, buscam oferecer-lhe apoio e suporte durante o tratamento, auxiliando no cuidado demandado por ele (MELO; PAULO, 2012).

Também foi encontrado, nessa categoria, que a família demanda aprender a conviver com o seu ente para amenizar o sofrimento (ALVAREZ; OLIVEIRA;XAVIER, 2012; ARAGÃO; MILAGRES; FIGLIE, 2009). Paula et al. (2014) ressaltam que a família, ao conviver com essa situação, vivencia diversas dificuldades e sentimentos negativos: tristeza, vergonha, sensação de "fundo do poço" etc. Enquanto a família busca ajudar o seu ente, ela, por muitas vezes, não toma para si o cuidado com a sua própria saúde, podendo adquirir problemas relacionados ao seu sofrimento vivido. Por isso,

Tabela 1. Caracterização dos artigos selecionados para a revisão integrativa do período de 2005 a 2015.

\begin{tabular}{|c|c|c|}
\hline Autores (ano) & Título & Categorias \\
\hline $\begin{array}{l}\text { Alvarez, Oliveira e } \\
\text { Xavier (2012) }\end{array}$ & $\begin{array}{l}\text { Grupo de apoio/suporte como estratégia de cuidado: importância para } \\
\text { familiares de usuários de drogas. }\end{array}$ & 1,2 \\
\hline $\begin{array}{l}\text { Aragão, Milagres e } \\
\text { Figlie (2009) }\end{array}$ & $\begin{array}{l}\text { Qualidade de vida e desesperança em familiares de dependentes } \\
\text { químicos. }\end{array}$ & 1,3 \\
\hline Araújo et al. (2012) & $\begin{array}{l}\text { Perfil clínico e sociodemográfico de adolescentes que permaneceram } \\
\text { e não permaneceram no tratamento em um CAPS-AD de Cuiabá/MT. }\end{array}$ & 2 \\
\hline $\begin{array}{l}\text { Azevedo e Miranda } \\
(2010)\end{array}$ & Práticas profissionais e tratamento ofertado nos CAPS-AD. & 2,3 \\
\hline Fonseca et al. (2014) & $\begin{array}{l}\text { Percepção de usuários de crack sobre o tratamento em um Centro de } \\
\text { Atenção Psicossocial, Álcool e outras Drogas. }\end{array}$ & 2,4 \\
\hline $\begin{array}{l}\text { Lisbôa, Brêda e } \\
\text { Albuquerque (2014) }\end{array}$ & $\begin{array}{l}\text { Concepções e práticas de acolhimento aos familiares na atenção } \\
\text { psicossocial especializada em álcool e outras drogas. }\end{array}$ & 4 \\
\hline $\begin{array}{l}\text { Mombelli, Marcon e } \\
\text { Costa (2010) }\end{array}$ & $\begin{array}{l}\text { Caracterização das internações psiquiátricas para desintoxicação de } \\
\text { adolescentes dependentes químicos. }\end{array}$ & 4 \\
\hline Nasiet et al. (2015) & $\begin{array}{l}\text { Tecnologias de cuidado em saúde mental para o atendimento ao } \\
\text { usuário de crack. }\end{array}$ & 4 \\
\hline $\begin{array}{l}\text { Oliveira e Mendonça } \\
\text { (2012) }\end{array}$ & $\begin{array}{l}\text { Membro da família com dependência química e consequente } \\
\text { sobrecarga sofrida pela família: pesquisa descritiva. }\end{array}$ & 2,3 \\
\hline Paula et al. (2014) & $\begin{array}{l}\text { Usuário de crack em situações de tratamento: experiências, } \\
\text { significados e sentidos. }\end{array}$ & 2 \\
\hline Paz e Colossi (2013) & Aspectos da dinâmica da família com dependência química. & 4 \\
\hline Reis e Moreira (2013) & $\begin{array}{l}\text { O crack no contexto familiar: uma abordagem fenomenológica. } \\
\text { Florianópolis. }\end{array}$ & 1,4 \\
\hline $\begin{array}{l}\text { Seadi e Oliveira } \\
(2009)\end{array}$ & $\begin{array}{l}\text { A terapia multifamiliar no tratamento da dependência química: um } \\
\text { estudo retrospectivo de seis anos. }\end{array}$ & 3 \\
\hline $\begin{array}{l}\text { Seleghim e Oliveira } \\
\text { (2013) }\end{array}$ & Influência do ambiente familiar no consumo de crack em usuários. & 1 \\
\hline Silva et al. (2012) & $\begin{array}{l}\text { Participação da família no tratamento dos usuários do centro de } \\
\text { atenção psicossocial de álcool e outras drogas. }\end{array}$ & 3,4 \\
\hline Vargens et al. (2009) & $\begin{array}{l}\text { Uso de drogas ilícitas e perspectivas críticas de familiares e pessoas } \\
\text { próximas, na cidade do Rio de Janeiro, Zona Norte, Brasil. }\end{array}$ & 1 \\
\hline $\begin{array}{l}\text { Zanatta, Garghetti e } \\
\text { Lucca (2012) }\end{array}$ & $\begin{array}{l}\text { O Centro de Atenção Psicossocial Álcool e outras Drogas sob a } \\
\text { percepção do usuário. }\end{array}$ & 2,4 \\
\hline
\end{tabular}


segundo Silva et al. (2012), essa família precisa exercer o seu papel em relaçáo ao tratamento do seu ente, mas é importante que ela também tenha consciência das suas necessidades para que seu sofrimento seja minimizado. Além disso, é preciso que os profissionais dos serviços de saúde mental sejam capazes de oferecer estratégias de cuidado centradas na família. Entretanto, conforme destacado por Constantinidis e Andrade (2015), de modo geral, os profissionais de saúde mental desconhecem ou não se sentem preparados para lidar com os familiares.

Alguns estudos (CAMPOS, 2001; ROMAGNOLI, 2004) atribuem essa situação à falta de capacitação, entretanto Constantinidis (2017) ressalta que essa realidade vai além do saber profissional, uma vez que, em sua maioria, os profissionais de saúde consideram o contexto familiar prejudicial ao usuário, sendo essa relação marcada por uma rivalidade, formando-se um campo de tensão. Em outras palavras, ao náo conseguir dar resposta às necessidades dos familiares, tão marcadas pelos encargos da convivência cotidiana com o seu ente, os profissionais sentem-se impotentes e se colocam contra esse sentimento, resistindo às possibilidades do encontro. Diante desse cenário, ressalta-se

[...] a importância de o profissional afirmar a diferença que o familiar apresenta em relaçáo a ele, para que as necessidades sejam explicitadas e negociadas e que ofertas de atenção e cuidado sejam feitas em consonância com os sujeitos dessa relação (CONSTANTINIDIS, 2017, p. 30).

De acordo com os textos analisados, a família entende que, por meio da implantação de políticas, o seu ente poderá cessar o uso de drogas. Por isso, um dado também encontrado nessa categoria foi a vontade de implantaçáo de políticas públicas de correçáo, puniçáo e isolamento social (VARGENS et al., 2009; SELEGHIM; OLIVEIRA, 2013). Além disso, infere-se que essa solicitaçáo pode estar relacionada: (1) à falta de informação da família sobre o modelo de atenção, preconizado nas políticas públicas em saúde, destinada a esse público, produzindo o entendimento de que a lógica da abstinência seja a única alternativa de tratamento; (2) à compreensão de que a reclusão pode proteger o seu ente das ameaças externas e dificultar o acesso às drogas; (3) à concepção de que ações de repressão podem provocar mudanças de comportamento do seu ente; (4) ao sofrimento vivenciado pela família; e (5) à sobrecarga familiar.

Entretanto, cabe ressaltar que essas demandas vinculadas à punição, correção e exclusão social não condizem com a proposta do modelo de atençáo psicossocial que norteia o processo de trabalho dos serviços de saúde mental. Conforme destacado na introdução deste trabalho, o referido modelo tem como proposta o desenvolvimento de estratégias de cuidado de base territorial, compreendendo o processo de saúde-doença enquanto um fenômeno social complexo e que, por isso, necessita de uma articulação intersetorial e uma abordagem interdisciplinar, bem como a construçáo de dispositivos territorializados e substitutivos à lógica manicomial. Suas açóes têm como pressuposto o acompanhamento das pessoas no seu meio social (território, família, comunidade, entre outros), visando à retomada de autonomia, ao resgate da cidadania, à abordagem mais ampla do cuidado e à reinserção social (PINTO et al., 2011).

\subsection{Estratégias de cuidado ofertadas às famílias}

Nesta categoria, os dados relacionam-se às práticas de cuidado ofertadas às famílias dos usuários que se encontram em acompanhamento nos serviços de saúde mental. Por meio da análise dos dados, identificaram-se as seguintes estratégias de cuidados: grupo terapêutico, reuniáo de familiares, aconselhamento e visitas domiciliares. De modo geral, todos os artigos analisados ressaltam a importância da oferta de cuidado para com a família. Porém, verificou-se que essas estratégias de cuidado são caracterizadas por orientaçôes relacionadas ao manejo para com o seu ente com necessidades decorrentes do uso do álcool e outras drogas, deixando em segundo plano o cuidado propriamente dito com essa família, ou seja, a família é vista com receptora das orientaçóes. Além disso, não foi possível identificar, nos artigos analisados, o protagonismo dos familiares no processo do cuidado.

De acordo com o Ministério da Saúde (BRASIL, 2004a), a participaçáo dos familiares no cotidiano dos serviços é uma das propostas dos CAPS. A família é o elo mais próximo que os usuários possuem com o mundo, tornando-se indispensável para o cuidado realizado nos serviços de saúde mental. As estratégias dirigidas às famílias devem ter como base o estímulo e o apoio necessário à construção de projetos terapêuticos voltados à reinserção familiar e social. Nesse contexto, Saraceno (2005) nos alerta sobre o risco de as açóes executadas de forma isolada, ou seja, sem a participação da família, limitarem-se a reproduzir técnicas que resultam na fragmentação dos serviços e dos usuários.

Reitera-se que, no campo da atenção psicossocial, o objeto do cuidado das equipes de saúde mental é a família em toda sua complexidade, entendendo-a como integrante e protagonista do processo do 
cuidado. Por isso, é imprescindível que a família seja acompanhada pelos serviços de saúde mental de maneira que suas necessidades sejam acolhidas. No momento em que a família recebe o cuidado e a orientação adequada, podendo compartilhar suas dificuldades, elas demonstram seu comprometimento com o cuidado ao seu ente. Sendo assim, torna-se importante promover espaços de atenção à família, inserindo-a no processo de reabilitação, corresponsabilizando-a pelo cuidado de seu familiar e dando visibilidade à sua ação cuidadora (CAVALHERI, 2010).

\subsection{Dificuldades para a inserção da família no tratamento do seu ente}

A não adesão dos familiares nas atividades ofertadas também foi identificada na análise dos dados. De acordo com os textos analisados, um fator que contribui para essa não adesão está relacionado aos conflitos gerados na família em função de possuir um membro com necessidades decorrentes do uso de álcool e outras drogas (ARAÚJO et al., 2012). De acordo com Nascimento, Souza e Gaino (2015), quando uma pessoa faz uso abusivo de álcool e outras drogas, além das consequências clínicas que podem ocorrer, agravam-se também os eventuais conflitos e as dificuldades existentes no cotidiano de seus familiares. Essa situação ocasiona desgastes tanto na esfera física quanto no âmbito psicológico dessa família. Nesse contexto, possuir uma rede de apoio, com funcionamento intersetorial, pode contribuir amplamente para a diminuição de conflitos e fortalecimento das relaçóes interpessoais. Em outras palavras, o trabalho intersetorial em rede pode ser uma resposta mais potente e resolutiva diante das diferentes necessidades apresentadas pela família, uma vez que estas articulam pessoas e instituiçóes que buscam soluçóes de maneira compartilhada na superação de problemas sociais. Além disso, a participação dos familiares em ações dentro de uma rede, tais como os grupos de apoio e orientação, favorecem a criação de espaços de trocas de experiências com outros familiares que vivenciam situações semelhantes e, consequentemente, podem ajudar a minimizar as dificuldades encontradas no cotidiano familiar.

O sentimento de sobrecarga (SILVA et al., 2012; OLIVEIRA; MENDONÇA, 2012) também é apontado como dificuldade. Soares e Munari (2007) definem a sobrecarga familiar como um conceito multidimensional com aspectos diversos, relacionados aos sintomas e comportamentos do usuário, que interferem na rotina e na dinâmica da família e que propiciam atingir várias dimensões da vida, como a saúde, o lazer, o trabalho, o bem-estar físico e psicológico e o relacionamento entre os membros da família. Nesse sentido, Pimenta e Romagnoli (2008) ressaltam que os serviços de saúde precisam elaborar estratégias que visem atender às necessidades da família.

O fato de a família acreditar que a internaçáo é a única solução para a resolutividade do problema (SEADI; OLIVEIRA, 2009) também foi identificado. Esse dado retrocede ao que está colocado na Política de Atenção Integral a pessoas com necessidades decorrentes do uso de álcool e outras drogas, promulgada em 2003 (BRASIL, 2003), uma vez que se contrapóe à lógica de reduçáo de danos, estratégia presente nos serviços de saúde mental, que deve se dar como uma açáo a ser desenvolvida no território, promovendo a construção de redes de suporte, visando produzir recursos que não sejam repressivos, mas comprometidos com a defesa da vida. Nesse sentido, o "locus" de intervençáo pode ser tanto os diferentes locais por onde circulam as pessoas com necessidades decorrentes do uso do álcool e outras drogas quanto os equipamentos de saúde, de educação, de trabalho, de promoção social, enfim, todos os recursos disponíveis na cidade.

A busca por soluçóes imediatistas (PAULA et al., 2014) também foi umas das justificativas para a não adesão da família. Essa não adesão ao tratamento, muitas vezes, ocorre pelo fato de a família desejar um tratamento rápido. Infere-se que tal realidade seja ainda reflexo do modelo biomédico adotado por muito tempo no campo da saúde. Esse modelo é limitador e tem como foco a cura da doença, sem a compreensão da complexidade existente em torno da problemática. Por isso, para o campo da saúde mental, náo deve ser aplicado. A questão do uso abusivo de álcool e outras drogas não deve ser compreendida como um problema exclusivamente psiquiátrico ou médico, pois suas implicações sociais, psicológicas, econômicas e políticas precisam ser consideradas na compreensão global do problema, levando-se em conta a tríade substância, pessoa e seu meio social (ORGANIZAÇÃO..., 2006).

Para o desfecho da análise de dados dessa categoria, verificou-se a falta de diversidade e de oferta de cuidado que correspondam às demandas apresentadaspela família (AZEVEDO; MIRANDA, 2010). De modo geral, os profissionais dos serviços de saúde mental concordam sobre a importância e a necessidade de cuidar tanto do membro quanto da família, mas vários fatores ainda contribuem para dificultar sua implantação e condução efetivas (ROSA, 2005; COLVERO; IDE; ROLIM, 2004). Segundo Villares e Mari (2005), muitas vezes as técnicas terapêuticas sobrelevam a família, sua 
singularidade, sua história, suas particularidades na relação com o seu familiar. Também, de acordo com Constantinidis e Andrade (2015), cada serviço ou equipe se organiza de maneira própria para abordar a família, mas nem sempre com o devido conhecimento de investigação das suas reais necessidades e condiçôes materiais, psicossociais, de saúde e de qualidade de vida. Com isso, as estratégias de cuidado ofertadas náo suprem as demandas apresentadas pelas famílias.

\subsection{A inserção da família no tratamento: quais os benefícios?}

Os dados desta categoria apresentam os benefícios encontrados com a inserção da família no tratamento do seu ente com necessidades decorrentes do álcool e outras drogas nos serviços de saúde mental. A maioria dos artigos analisados ressalta que $\boldsymbol{a}$ participaçáo da familia favorece a permanência do seu ente no tratamento (FONSECA et al., 2014; MOMBELLI; MARCON; COSTA, 2010; ZANATTA; GARGHETTI; LUCCA, 2012; PAZ; COLOSSI, 2013), ou seja, a adesão do ente ao tratamento pode estar relacionada ao grau de envolvimento e participaçáo da família no processo do cuidado. Tal dado corrobora Araújo et al. (2012), que ressaltam que a família pode contribuir para a permanência no tratamento. Os autores acrescentam também os seguintes benefícios: auxílio no uso da estratégia de redução do uso e diminuição do sofrimento tanto do seu membro com necessidades decorrentes do uso de álcool e outras drogas quanto da família. Além disso, adesão da família promove melhorias no processo de cuidado do seu ente, nas relações familiares e, consequentemente, na qualidade de vida da família assistida (BRAUN; ZANON; HALPERN, 2014).

Ainda dentro dessa discussão, destacou-se que o apoio da família ao seu ente melhora a adesáo ao tratamento (SILVA et al., 2012; REIS; MOREIRA, 2013; LISBÔA; BRÊDA; ALBUQUERQUE, 2014). Os usuários que contam com a participação da família no tratamento se sentem mais encorajados e esperançosos, resultando em uma diminuição do isolamento social, o que, consequentemente, produz efeitos positivos no processo de cuidado (ALVAREZ; OLIVEIRA; XAVIER, 2012).

Além disso, a redução de internaçóes prolongadas foi um dos principais benefícios colocados por Nasiet et al. (2015), com a inserção da família no tratamento. Essa realidade corrobora os dados colocados pela Política Nacional de Atenção Integral a Usuários de Álcool e Outras Drogas, que ressalta que as reduçóes das internaçóes prolongadas estão ocorrendo significativamente em funçáo: do processo de consolidação do modelo de atençáo psicossocial; do fortalecimento das redes de atenção; das açôes de intersetorialidade; e das estratégias que agregam a família como agente contribuinte no processo do cuidado (BRASIL, 2003). Além disso, pondera-se que tal redução tenha ocorrido em função da expansão dos CAPS AD, que também têm como um dos seus objetivos evitar as internaçóes e/ou reinternaçôes em hospitais psiquiátricos. Para tanto, além da inserção da família no processo de cuidado, torna-se necessário o desenvolvimento de um leque de práticas, tais como: oferta de atendimento diário; açôes de reinserção social e do exercício dos direitos civis; fortalecimento da rede de apoio e, claro, dos laços familiares.

\section{Conclusão}

Diante dos resultados obtidos, foi possível identificar tanto os desafios vividos pelos familiares quantos os enfrentados pelos serviços de saúde mental em relação à família. No que se refere aos desafios da família, ressalta-se: a busca por melhor convivência com o seu ente; a sobrecarga familiar; e o desejo de ajudar seu membro com necessidade decorrentes do uso do álcool e outras drogas. Já em relação aos serviços, destaca-se a dificuldade de oferta de estratégia de cuidados condizente com as demandas da família, bem como a inserçáo dela de forma participativa no processo do cuidado.

De modo geral, a análise dos dados mostrou que a atuação da família no processo de cuidado do seu familiar tem sua importância, podendo garantir melhorias no seu tratamento, dando-lhe apoio e suporte, além de favorecer a adesáo ao tratamento e a redução das internações prolongadas. Diante disso, faz-se necessário o investimento em estratégias de cuidado, de forma permanente, tanto com o enfoque no manejo com o seu ente quanto para as demandas concretas da família, uma vez que a inserção da família pode ser benéfica ao processo de cuidado.

Com isso, os estudos encontrados destacam a importância da família nesse processo de cuidado com o seu ente, sendo um dos principais agentes contribuintes para uma melhor adesão e resolutividade do tratamento, não negligenciando também o seu papel de ser cuidada.

Nessa perspectiva, surge a necessidade de se repensar a inserçẫo das famílias nos serviços substitutivos de saúde mental, bem como a implantação de políticas públicas que reforcem a importância da sua participação nesse processo de cuidado, como agentes corresponsáveis, e que enfatizem as atribuiçóes tanto das equipes de saúde mental com a família quanto 
desta com o seu ente com necessidades decorrentes do álcool e outras drogas.

Cabe salientar as limitaçôes deste estudo, tais como a busca limitada por trabalhos configurados como artigos científicos, ou seja, não foram incluídos livros, teses e dissertaçôes. Além disso, também não foram inseridos artigos em outros idiomas. Por fim, ressalta-se a importância da realização de pesquisas que abordem esse tema e contribuam para ampliar as discussóes sobre ele.

\section{Referências}

ALVAREZ, S. Q.; OLIVEIRA, A. M. N.; XAVIER, D. M. Grupo de apoio/suporte como estratégia de cuidado: importância para familiares de usuários de drogas. Revista Gauicha de Enfermagem, Porto Alegre, v. 33, n. 2, p. 102-108, 2012.

ARAGÃO, A.; MILAGRES, E.; FIGLIE, N. Qualidade de vida e desesperança em familiares de dependentes químicos. Psico-USF, Itatiba, v. 14, n. 1, p. 117-123, 2009.

ARAÚJO, N. B. et al. Perfil clínico e sociodemográfico de adolescentes que permaneceram e não permaneceram no tratamento em um CAPS-AD de Cuiabá/MT. Jornal Brasileiro de Psiquiatria, Rio de Janeiro, v. 61, n. 4, p. 227-234, 2012.

AZEVEDO, D. M.; MIRANDA, F. A. N. Práticas profissionais e tratamento ofertado nos CAPS-AD. Escola Anna Nery Revista de Enfermagem, Rio de Janeiro, v. 14, n. 4, p. 56-63, 2010.

BARDIN L. Análise de conteúdo. Lisboa: Edições 70, 2009.

BERNARDI, I. E. Prevenção e tratamento no uso de substâncias causadoras de dependência. 2002. $50 \mathrm{f}$. Monografia (Licenciatura de Psicologia) - Universidade do Norte Paulista, São José do Rio Preto, 2002.

BRASIL. Congresso Nacional. Lei no 10.216, de 6 de abril de 2001. Dispóe sobre a proteçáo e os direitos das pessoas portadoras de transtornos mentais e redireciona o modelo assistencial em saúde mental. Diário Oficial da Uniāo, Poder Executivo, Brasília, DF, 9 abr. 2001.

BRASIL. Ministério da Saúde. Secretaria Executiva Coordenação Nacional de DST e AIDS. A politica do Ministério da Saúde para a atenção integral a usuários de álcool e outras drogas. Brasília: Ministério da Saúde, 2003. (Série B: Textos Básicos de Saúde).

BRASIL. Ministério da Saúde. Legislação em saúde mental 1990-2004. 5. Brasília: Editora MS, 2004a.

BRASIL. Ministério da Saúde. Secretaria de Atenção à Saúde. Departamento de Açóes Programáticas Estratégicas. Saúde mental no SUS: os Centros de Atenção Psicossocial. Brasília: Ministério da Saúde, 2004b.

BRASIL. Ministério da Saúde. Portaria no 3.088, de 23 de dezembro de 2011. Institui a Rede de Atenção Psicossocial para pessoas com sofrimento ou transtorno mental e com necessidades decorrentes do uso de crack, álcool e outras drogas, no âmbito do Sistema Único de Saúde. Diário Oficial da Uniāo, Poder Executivo, Brasília, DF, 26 dez. 2011.

BRAUN, L. M.; ZANON, L. L. D.; HALPERN, S. C. A família do usuário de drogas no CAPS: um relato de experiência. Revista da SPAGESP, Ribeirão Preto, v. 15, n. 2, p. 122-140, 2014.

CAMPOS, R. O. Clínica: a palavra negada: sobre as práticas clínicas nos serviços substitutivos de saúde mental. Saúde em Debate, Rio de Janeiro, v. 25, n. 8, p. 98-111, 2001.

CAVALHERI, S. C. Transformaçōes do modelo assistencial em saúde mental e seu impacto na família. Revista Brasileira de Enfermagem, Brasília, v. 63, n. 1, p. 51-57, 2010.

COLVERO, L. A.; IDE, C. A.; ROLIM, M. A. Família e doença mental: a difícil convivência com a diferença. Revista da Escola de Enfermagem da USP, São Paulo, v. 38, n. 2, p. 197-204, 2004.

CONSTANTINIDIS, T. Profissionais de saúde mental e familiares de pessoas com sofrimento psíquico: encontro ou desencontro? Psicologia USP, São Paulo, v. 28, n. 1, p. 23-32, 2017.

CONSTANTINIDIS, T.; ANDRADE, A. N. Demanda e oferta no encontro entre profissionais de saúde mental e familiares de pessoas com sofrimento psíquico. Ciência \& Saúde Coletiva, Rio de Janeiro, v. 20, n. 2, p. 333-342, 2015.

FERREIRA, A. B. H. Dicionário Aurélio básico da Lingua Portuguesa. Rio de Janeiro: Nova Fronteira, 1988.

FONSECA, R. L. et al. Percepçâo de usuários de crack sobre o tratamento em um Centro de Atençáo Psicossocial, álcool e outras drogas. Revista de APS, Juiz de Fora, v. 17, n. 2, p. 214-222, 2014.

INSTITUTO NACIONAL DE POLÍTICAS PÚBLICAS DO ÁLCOOL E OUTRAS DROGAS - INPAD. Levantamento nacional de álcool e drogas. São Paulo: UNIFESP, 2012.

LISBÔA, G. L. P.; BRÊDA, M. Z.; ALBUQUERQUE, M. C. S. Concepçôes e práticas de acolhimento aos familiares na atenção psicossocial especializada em álcool e outras drogas. Revista da Rede de Enfermagem do Nordeste, Fortaleza, v. 15, n. 2, p. 264-272, 2014.

MELO, P. F.; PAULO, M. A. L. A importância da família na recuperação do usuário de álcool e outras drogas. Saúde Coletiva em Debate, Pernambuco, v. 1, n. 2, p. 4151, 2012.

MOMBELLI, M. A.; MARCON, S. S.; COSTA, J. B. Caracterização das internaçôes psiquiátricas para desintoxicação de adolescentes dependentes químicos. Revista Brasileira de Enfermagem, Brasília, v. 63, n. 5, p. 735740, 2010.

NASCIMENTO, L. T. R.; SOUZA, J.; GAINO, L. V. Relacionamento entre familiar e usuário de álcool em 
tratamento em um centro de atenção psicossocial especializado. Texto \& Contexto Enfermagem, Florianópolis, v. 24, n. 3, p. 834-841, 2015.

NASIET, C. et al. Tecnologias de cuidado em saúde mental para o atendimento ao usuário de crack. Revista Gaúcha de Enfermagem, Porto Alegre, v. 36, n. 1, p. 9297, 2015.

OLIVEIRA, E.; MENDONÇA, J. Membro da família com dependência química e conseqüente sobrecarga sofrida pela família: pesquisa descritiva. Revista Brasileira de Enfermagem, Brasília, v. 11, n. 1, p. 11-17, 2012.

ORGANIZAÇÃO MUNDIAL DA SAÚDE - OMS. Prioridades de controle de doenças relacionadas com distur rbios de abuso mentais, neurológicos, de desenvolvimento $e$ de substância. Genebra: OMS, 2006.

PAULA, M. L. et al. Usuário de crack em situações de tratamento: experiências, significados e sentidos. Saúde e Sociedade, São Paulo, v. 23, n. 1, p. 118-130, 2014.

PAZ, F. M.; COLOSSI, P. M. Aspectos da dinâmica da família com dependência química. Estudos de Psicologia, Natal, v. 18, n. 4, p. 551-558, 2013.

PIMENTA, E. S.; ROMAGNOLI, R. C. A relação com as famílias no tratamento dos portadores de transtorno mental realizado no Centro de Atenção Psicossocial. Pesquisas e Práticas Psicossociais, São João del Rei, v. 3, n. 1, p. 75-84, 2008.

PINTO, D. M. et al. Projeto terapêutico singular na produção do cuidado integral: uma construção coletiva. Texto \& Contexto Enfermagem, Florianópolis, v. 20, n. 3, p. 493-502, 2011.

RAUPP, L. M.; COSTA, J. M. O ECA e as práticas de atendimento à drogadição na adolescência. In: CONGRESSO INTERNACIONAL DE PEDAGOGIA SOCIAL, 1., 2006, São Paulo. Anais... São Paulo: Faculdade de Educação, Universidade de São Paulo, 2006.

REIS, H. F. T.; MOREIRA, T. O. O crack no contexto familiar: uma abordagem fenomenológica. Texto \& Contexto Enfermagem, Florianópolis, v. 22, n. 4, p. 11151123, 2013.

ROMAGNOLI, R. C. Trabalhando com famílias na rede de saúde mental: dificuldades e desafios. Pulsional: Revista de Psicanálise e Clínica Social, São Paulo, v. 17, n. 180, p. 71-80, 2004.
ROSA, L. C. S. A inclusão da família nos projetos terapêuticos em saúde mental. Psicologia em Revista, Belo Horizonte, v. 11, n. 18, p. 205-218, 2005.

RUSSEL, C. L. Na overview of the integrative research review. Progress in Transplantation, Thousand Oaks, v. 15, n. 1, p. 8-12, 2005

SARACENO, B. Desafios dos novos serviços de saúde mental no território. In: SEMINÁRIO SOBRE SAÚDE MENTAL NA ESCOLA DE ENFERMAGEM DA USP, 2005, Rio de Janeiro. Anais... Rio de Janeiro: Fiocruz, 2005.

SEADI, S. M.; OLIVEIRA, M. S. A terapia multifamiliar no tratamento da dependência química: um estudo retrospectivo de seis anos. Psicologia Clínica, Rio de Janeiro, v. 21, n. 2, p. 363-378, 2009.

SELEGHIM, M. R.; OLIVEIRA, M. L. F. Influência do ambiente familiar no consumo de crack em usuários. Acta Paulista de Enfermagem, São Paulo, v. 26, n. 3, p. 263-268, 2013

SILVA, B. L. C. et al. Participação da família no tratamento dos usuários do centro de atenção psicossocial de álcool e outras drogas. Revista Brasileira de Pesquisa em Saúde, Vitória, v. 4, n. 14, p. 61-68, 2012.

SOARES, C. B.; MUNARI, D. B. Sobrecarga em familiares de pessoas com transtorno mental. Ciência, Cuidado e Saúde, Maringá, v. 6, n. 3, p. 357-362, 2007.

VARGENS, O. M. C. et al. Uso de drogas ilícitas e perspectivas críticas de familiares e pessoas próximas, na cidade do Rio de Janeiro, Zona Norte, Brasil. Revista Latino-Americana de Enfermagem, Rio de Janeiro, v.17, p. 776-782, 2009. Edição Especial.

VILLARES, C. C.; MARI, J. J. Esquizofrenia e contexto familiar. In: SHIRAKAWA, I.; CHAVES, A. C.; MARI, J. J. (Ed.). O desafio da esquizofrenia. São Paulo: Lemos Editorial, 2005. p. 243-55.

YASUI, S.; COSTA-ROSA, A. A Estratégia Atenção Psicossocial: desafio na prática dos novos dispositivos de Saúde Mental. Saúde em Debate, Rio de Janeiro, v. 32, n. 2, p. 27-37, 2008.

ZANATTA, A. B.; GARGHETTI, F. C.; LUCCA, S. R. O Centro de Atenção Psicossocial Álcool e outras Drogas sob a percepçáo do usuário. Revista Baiana de Saúde Pública, Salvador, v. 36, n. 1, p. 225-237, 2012.

\section{Contribuição dos Autores}

Ambos os autores contribuíram igualmente na elaboração do artigo. Todos os autores aprovaram a versão final do texto. 